\title{
SECUELAS DE COVID 19 EN GUSTO Y OLFATO: UNA BREVE REVISIÓN BIBLIOGRÁFICA
}

\section{REVISIÓN BIBLIOGRÁFICA}

CHAVES, leda Bezerra ${ }^{1}$, FECURY, Amanda Alves², OLIVEIRA, Euzébio de ${ }^{3}$, DENDASCK, Carla Viana ${ }^{4}$, DIAS, Claudio Alberto Gellis de Mattos $^{5}$

CHAVES, leda Bezerra. Et al. Secuelas de COVID 19 en gusto y olfato: una breve revisión bibliográfica. Revista Científica Multidisciplinar Núcleo do Conhecimento. Año. 06, Ed. 11, Vol. 01, págs. 150-166. Noviembre de 2021. ISSN: 2448-0959, Enlace de acceso: https://www.nucleodoconhecimento.com.br/salud/secuelas-decovid-19, DOI: 10.32749/nucleodoconhecimento.com.br/salud/secuelas-de-covid-19

\section{RESUMEN}

Los virus son un ser vivo que no está formado por la estructura celular. Los virus pueden transmitirse por contacto directo con individuos infectados o indirectamente desde superficies contaminadas. Definido como una nueva variedad de coronavirus, el COVID 19 hizo que la Organización Mundial de la Salud (OMS) declarara a principios de 2020 una crisis en la salud pública mundial. Teniendo en cuenta la alta transmisibilidad de este virus, fue necesario adoptar medidas para prevenir la transmisión y la infección. Los síntomas causados por COVID-19 suelen ser fiebre, tos seca, dificultad para respirar (disnea), cansancio (fatiga), dolor de garganta, dolor

\footnotetext{
${ }^{1}$ Estudiante de la Escuela Secundaria Técnica Integrada en Alimentación, Instituto de Educación Básica, Técnica y Tecnológica de Amapá (FIPA).

2 Biomédico, Doctor en Enfermedades Tópicas, Profesor e investigador del Curso Médico del Campus Macapá, Universidad Federal de Amapá (UNIFAP).

${ }^{3}$ Biólogo, Doctor en Enfermedades Tópicas, Profesor e investigador del Curso de Educación Física de la Universidad Federal de Pará (UFPA).

${ }^{4}$ Teólogo, Doctor en Psicoanálisis Clínico. Ha estado trabajando durante 15 años con Metodología Científica (Método de Investigación) en la Guía de Producción Científica de estudiantes de Maestría y Doctorado. Especialista en Investigación de Mercados e Investigación enfocada en salud. Estudiante de doctorado en Comunicación y Semiótica (PUC SP).

${ }^{5}$ Biólogo, Doctor en Teoría e Investigación del Comportamiento, Profesor e investigador del Curso de Grado de Química del Instituto de Educación Básica, Técnica y Tecnológica de Amapá (IFAP) y del Programa de Posgrado en Educación Profesional y Tecnológica (PROFEPT IFAP).
}

RC: 101281

Disponible: https://www.nucleodoconhecimento.com.br/salud/secuelas-de-covid-19 
de cabeza y diarrea. Otros síntomas, en menor medida, son anosmia (pérdida del olfato), hiposmia (disminución del olfato) y ageusia (pérdida del sentido del gusto). El objetivo de este fue repasar los dos últimos años sobre las secuelas del COVID 19 en sabor y olfato. Se realizó una breve revisión bibliográfica en artículos científicos sobre las secuelas de COVID 19 en sabor y olfato, entre 2020 y 2021, en portugués, en la base de datos de búsqueda Google Scholar. Las mujeres y los jóvenes son los más afectados por las secuelas del gusto y el olfato provocadas por el COVID-19. No existen tratamientos específicos y científicamente probados para las diversas disfunciones, pero el más indicado es la práctica del entrenamiento olfativo. Los estudios relacionados con las disfunciones son limitados, principalmente, en Brasil y cuando se analizan como secuelas. La continuidad de la investigación científica es indispensable, porque sólo este proceso podrá dilucidar las dudas que aún existen y generar tratamientos adecuados para las personas que desarrollaron COVID-19.

Palabras clave: Virus, COVID 19, Disosmia, Disgeusia.

\section{INTRODUCCIÓN}

Los virus son un ser vivo que, a diferencia de los demás, no está formado por células. Por lo general, tiene un ácido nucleico (que puede ser ADN o ARN), cubierto por una "cápsula" de proteína. Algunos todavía están cubiertos por "pedazos" de membrana celular, que crean una "envoltura" a su alrededor. A menudo son más pequeños que una célula y los parasitan, entrando en ellos y utilizando sus estructuras para producir más virus (son parásitos intracelulares obligatorios) (Brandão, 2015; They, 2020).

Los virus pueden transmitirse por contacto directo con individuos infectados o indirectamente desde superficies contaminadas. Se transmiten de un individuo a otro a través de gotas de agua en forma de vapor liberado en el aliento o durante el proceso de tos o estornudos. Las gotas más pequeñas liberadas junto con el vapor de agua durante estos procesos se suspenden en el aire propagando el virus en áreas más grandes y por más tiempo. (Brasil, 2021). En contacto con uno de estos 
medios de transmisión los virus invaden las células mucosas de las vías respiratorias y digestórias (Stephens et al., 2009; Silva et al., 2020).

Para reproducirse los virus se unen a la superficie de la membrana celular. Después de esta unión puede penetrar en la célula o puede "inyectar" su material genético (ADN o ARN) en su citoplasma. Una vez dentro de las células, el material genético del virus se copia varias veces, utilizando las reacciones químicas que puede hacer. Del mismo modo, otras reacciones químicas de la célula se utilizan para hacer las "cubiertas" de proteínas (cápsides). Así se montan nuevos virus dentro de una célula $y$, para salir e invadir nuevas células, se rompe la membrana de quienes los fabricaron (They, 2020; Silva et al., 2020a).

Definido como una nueva variedad de coronavirus, el COVID 19 hizo que la Organización Mundial de la Salud (OMS) declarara a principios de 2020 una crisis en la salud pública mundial (Souza et al., 2020). Estos virus, con una alta tasa de transmisión, consisten en envolturas de lípidos y proteínas (trozo de membrana de una célula), y cápsides de proteínas, con una sola cinta de arn (ácido nucleico), y con forma de corona externa (Silva et al., 2020). Forman parte de la familia de virus que generan resfriados comunes a infecciones más graves, como el Síndrome Respiratorio de Oriente Medio (MERS) y el Síndrome Respiratorio Agudo Severo (SARS) (Brasil, 2021; 2021a).

Teniendo en cuenta la alta transmisibilidad de este virus, es necesario adoptar medidas para prevenir la transmisión y la infección. Entre algunas de estas acciones preventivas, destacamos la no permanencia en lugares cerrados y el aislamiento de las personas infectadas (Stephens et al., 2009).

Las formas consideradas más eficientes y para evitar la contaminación (profilaxis) incluyen: lavado de manos, distanciamiento social, aireación de ambientes y su exposición a la luz solar, limpieza de objetos y superficies, prohibición de aglomeraciones y el uso de máscaras (bloqueadores eficientes de gotitas respiratorias dispersas, incluso a distancias reducidas con contacto directo o indirecto) (García, 2020). Estas medidas de control han demostrado su eficacia, a 
través de análisis y estudios científicos, para reducir la contaminación y la diseminación viral (Soares et al., 2021).

Los síntomas causados por COVID-19 en general son fiebre, tos seca, dificultad para respirar (disnea), cansancio (fatiga), dolor de garganta, dolor de cabeza y diarrea (Silva et al., 2020). Otros síntomas, en menor medida son anosmia (pérdida del olfato), hiposmia (disminución del olfato) y ageusia (pérdida del sentido del gusto) (Iser et al., 2020).

Las secuelas pueden definirse como un cambio en el funcionamiento de las células y/o en la forma y funcionamiento de los órganos causando un defecto permanente o no en el individuo (Filho, 2011; Vana y Schiozer, 2013).

Entre las diversas secuelas encontradas en individuos que tenían COVID19 se encuentran las de naturaleza psicológica y biológica, como cambios en los sistemas respiratorio, cardiovascular, posibles cambios cutáneos y neurológicos (depresión y ansiedad) (Estrela et al., 2021).

Un conjunto de investigaciones científicas apunta a daños a largo plazo (después de 6 semanas o persistentes más allá de las 6 semanas desde el inicio de los síntomas del coronavirus) en el sistema sensorial, con énfasis en las secuelas olfativas y gustativas, por ejemplo, disosmia (percepción distorsionada de los olores) y disgeusia (percepción distorsionada de los sabores de los alimentos). También puede haber trastornos del metabolismo de la glucosa (reacciones químicas), hiperlipidemia (aumento de la cantidad de grasa en la sangre), desregulación del metabolismo de los lípidos (reacciones químicas), trastorno de estrés postraumático (uno de los tipos de trastornos de ansiedad) y capacidad pulmonar afectada, daño al hígado (hígado) y al sistema renal (riñones), y posiblemente en el sistema reproductivo (Sesapr, 2020; Grendene et al., 2021).

Las disfunciones olfativas tienen una clasificación cuantitativa, en la que hay anosmia (no detección de olores), hiposmia (limitación en la detección de olores), hiperosmia (aumento de la capacidad de detectar olores) y disosmia (percepción 
distorsionada de olores) (Cardoso, 2018). Mientras que las disfunciones cuantitativas en el gusto se pueden clasificar en hipogeusia (detección parcial del gusto), hipergeusia (aumento de la capacidad de percepción gustativa), ageusia (pérdida total del gusto) y disgeusia (distorsión en el gusto) (Barros et al., 2015; Gomes et al., 2020; Machado e Machado, 2020).

La subclasificación cualitativa de la disosmia (alteración olfativa) es diversa, entre los ejemplos se pueden encontrar parosmia (percepción distorsionada y desagradable de los olores), fantosmia (percepción del olor en ausencia de partículas odoríferas) y agnosmia (incapacidad para clasificar diferentes olores) (Cardoso, 2018). La disgeusia (alteración gustativa) tiene una subclasificación cualitativa, también diversificada, entre ejemplos, parageusia (percepción inadecuada del gusto por estímulo) y fantogeusia (percepción gustativa desagradable en ausencia de estímulo) (Machado y Machado, 2020).

A pesar de las notas, se necesitan más estudios en relación con las numerosas y diversas secuelas debidas a Covid-19 (Grendene et al., 2021), incluidos los afectados con síntomas reducidos y asintomáticos (Uzun, 2020).

\section{GOL}

Hacer una revisión bibliográfica de los últimos dos años sobre las secuelas del COVID 19 en sabor y olfato.

\section{MÉTODO}

Se realizó una breve revisión bibliográfica en artículos científicos sobre las secuelas de COVID 19 en sabor y olfato, entre 2020 y 2021, en portugués, en la base de datos de búsqueda Google Scholar. Se utilizaron las palabras clave (o descriptores) "Gustación y COVID19" y "Olor y COVID 19". Se encontraron un total de 1.777 resultados y se utilizaron 10 artículos para componer esta breve revisión. Esto permitió que la revisión se hiciera a partir de las producciones académicas más actualizadas (Capes, 2012). 
Los artículos con contenido de COVID 19 y secuelas en sabor y olor se utilizaron, en portugués, dentro del límite de período de la revisión. Se excluyeron los artículos que no cumplían con este contenido y/o período de tiempo.

\section{RESULTADOS Y DISCUSIÓN}

La Tabla 01 muestra el número de artículos encontrados por descritos y el número de artículos utilizados dentro de los criterios metodológicos.

Tabla 1 - Número de artículos encontrados en la base de datos según descriptores y artículos utilizados

\begin{tabular}{|c|c|c|c|c|}
\hline BASE DE DADOS & DESCRITOR & \begin{tabular}{|c|} 
NUMERO \\
ARTIGOS \\
ENCONTRADOS \\
\end{tabular} & $\begin{array}{c}\text { NUMERO } \\
\text { ARTIGOS } \\
\text { UTILIZADOS } \\
\end{array}$ & $\begin{array}{c}\text { AUTOR E ANO DOS } \\
\text { ARTIGOS } \\
\text { UTILIZADOS } \\
\end{array}$ \\
\hline \multirow{10}{*}{ Google acadêmico } & \multirow{7}{*}{ Gustação e COVID19 } & \multirow{7}{*}{237} & \multirow{7}{*}{7} & PIMENTEL, 2020 \\
\hline & & & & $\begin{array}{l}\text { GRENDENE et al., } \\
2021\end{array}$ \\
\hline & & & & SANTOS et al., 2020 \\
\hline & & & & COSTA et al., 2020 \\
\hline & & & & SOUZA et al., 2021 \\
\hline & & & & $\begin{array}{c}\text { NOGUEIRA et al., } \\
2021\end{array}$ \\
\hline & & & & NUNES et al., 2020 \\
\hline & \multirow{3}{*}{ Olfato e COVID 19} & \multirow{3}{*}{1540} & \multirow{3}{*}{3} & KOSUGI et al., 2020 \\
\hline & & & & BRITO e SLVA, 2020 \\
\hline & & & & $\begin{array}{c}\text { LOPES e DE ABREU, } \\
2021\end{array}$ \\
\hline
\end{tabular}

RC: 101281

Disponible: https://www.nucleodoconhecimento.com.br/salud/secuelas-de-covid-19 
La Tabla 02 - muestra los métodos utilizados en cada artículo seleccionado para esta revisión, los resultados y las conclusiones encontradas.

\begin{tabular}{|c|c|c|c|}
\hline $\begin{array}{c}\text { AUTOR E ANO } \\
\text { DOS ARTIGOS } \\
\text { UTILIZADOS } \\
\end{array}$ & $\begin{array}{l}\text { TIPO DE } \\
\text { MÉTODO }\end{array}$ & RESULTADOS & CONCLUSÃO \\
\hline PIMENTEL, 2020 & $\begin{array}{l}\text { Pesquisa } \\
\text { qualitativa } \\
\text { descritiva, } \\
\text { revisão } \\
\text { bibliográfica da } \\
\text { literatura }\end{array}$ & \begin{tabular}{|} 
Estudos dassificaram as disfunções como: \\
anosmia/hiposmia ou ageusia e \\
hipogeusia/disgeusia. Pacientes tiveram os sintomas \\
disfuncionais tanto no olfato quanto na gustação. \\
Não são considerados danos permanentes.
\end{tabular} & $\begin{array}{c}\text { Identificação hiposmia, anosmia, fantosmia e } \\
\text { parosmia, com preval ência entre } 22,7 \% \text { a } 88,8 \% \text {, } \\
\text { associadas ou não hipogeu sia e ageusia Futuros } \\
\text { estudos epi demi ológicos devem esclarecer como } \\
\text { esses sintomas são causados. }\end{array}$ \\
\hline $\begin{array}{l}\text { SANTOS et al }= \\
2020\end{array}$ & $\begin{array}{l}\text { Revisão } \\
\text { Integrativa da } \\
\text { literatura }\end{array}$ & $\begin{array}{c}\text { Preval ência das disfunções sensoriais provocadas } \\
\text { pela COVD-19. Anosmia e disgeusia como } \\
\text { sintomas neurológicos mais frequentes. Pacientes } \\
\text { que tiveram quadro leve a moderado de COVID-19. } \\
\text { Aumento da idade dos pacientes e quadros mais } \\
\text { severos da doença representam menos al terações. }\end{array}$ & $\begin{array}{l}\text { Sintese de informações de vários paises, } \\
\text { caracterizando as disfunções olfativas e gustativas } \\
\text { como sintomas iniciais. Repercu ssões após alta dos } \\
\text { pacientes. Necessários estudos sobre as } \\
\text { probl emáticas e investigações mais detalhadas. Os } \\
\text { distúrbios poderão ser estudados em um periodo de } \\
\text { tempo maior. }\end{array}$ \\
\hline $\begin{array}{l}\text { NOGUEIRA et al ., } \\
2021\end{array}$ & $\begin{array}{l}\text { Revisão } \\
\text { descritiva }\end{array}$ & $\begin{array}{c}\text { A infecção nos neurônios causa sintomas } \\
\text { neurológicos como anosmia. Não há explicação } \\
\text { exata acerca da ocorrência dos distúrbios olfatórios. } \\
\text { Danos no sistema nervoso central e epitélio nasal, } \\
\text { cau sam a di sosmia e a disgeusia. }\end{array}$ & $\begin{array}{l}\text { Os probl emas olfativos e gustativo ocorrem } \\
\text { previamente em diferentes intensi dades. Não há } \\
\text { evidências cientificas para o tratamento desses } \\
\text { distúrbios. É importante a realização de estudos } \\
\text { acerca do assunto a fim de que se melhore os } \\
\text { procedimentos no tratamento nos casos, } \\
\text { principalmente, nos casos com sequel as de longo } \\
\text { prazo. }\end{array}$ \\
\hline $\begin{array}{c}\text { COSTA et al., } \\
2020\end{array}$ & $\begin{array}{l}\text { Revisão } \\
\text { Sistemática }\end{array}$ & $\begin{array}{l}\text { Sintomas neurológicos que ocorrem no sistema } \\
\text { nervoso periférico causam as di sfunções olfativa e } \\
\text { gustativa. Pacientes com quadro leve a moderado } \\
\text { apresentaram hipogeusia e hiposmia, não há } \\
\text { registros do inicio, duração e resolução dos } \\
\text { sintomas. Os pacientes com perda de olfato tiveram } \\
\text { menor taxa de internação, compar ados com os } \\
\text { pacientes sem perda de olfato. }\end{array}$ & $\begin{array}{l}\text { Os distúrbios olfativos e/ou gustativos podem } \\
\text { ocorrer em intensidades variáveis, com inicio junto } \\
\text { com os sintomas prévios da infecção. Não há } \\
\text { evidências cientificas acerca do tratamento destes } \\
\text { distúrbios. }\end{array}$ \\
\hline
\end{tabular}




\begin{tabular}{|c|c|c|c|}
\hline $\begin{array}{c}\text { BRITO e SIVA, } \\
2020\end{array}$ & $\begin{array}{c}\text { Revisão da } \\
\text { literatura }\end{array}$ & $\begin{array}{l}\text { Associação de manifestações neurológicas e a } \\
\text { COVID-19. Entre elas os distúrbios do olfato e } \\
\text { paladar, como a hiposmia, a anosmia, a disgeusia, } \\
\text { hipogeusia e ageusia. Os mecanismos exatos da } \\
\text { neuroinvasão causada pela COVID-19 ainda são } \\
\text { desconhecidos. }\end{array}$ & $\begin{array}{l}\text { Ocorre uma inci dência maior de danos no si stema } \\
\text { nervoso em quadros agudos da virose. Entretanto a } \\
\text { classificação dos casos agudos e crônicos ainda hoje } \\
\text { não é consenso. São necessários mais estu dos sobre } \\
\text { as sequelas a longo prazo. }\end{array}$ \\
\hline $\begin{array}{c}\text { SOUZA et al., } \\
2021\end{array}$ & Relato de casos & $\begin{array}{c}\text { Ano smia nos pacientes é uma manifestação } \\
\text { sintomal ógica recorrente. Fundamental a descrição } \\
\text { de relatos de casos a fim de esclarecer as } \\
\text { ocorrências de sequel as gustativas olfativas com } \\
\text { objetivo de realializar o manejo da recuperação. }\end{array}$ & $\begin{array}{l}\text { As disfunções devem ser estudadas com maior rigor } \\
\text { e por maior periodo de tempo. A COVID-19 afeta } \\
\text { as células do epitélio olf ativo, possivelmente } \\
\text { alterando a neurotransmissão. }\end{array}$ \\
\hline $\begin{array}{l}\text { LOPES e DE } \\
\text { ABREU } 2021\end{array}$ & $\begin{array}{c}\text { Metodologia para } \\
\text { tratamento }\end{array}$ & $\begin{array}{c}\text { Possiveis danos neurológicos em nivel celular } \\
\text { decorrentes da COVID-19. Pacientes recuperados } \\
\text { ainda relatam alterações, que podem ser } \\
\text { irreversiveis, nos sentidos olf ativo e gustativo. }\end{array}$ & $\begin{array}{l}\text { As sequelas causadas pela doença podem ser de } \\
\text { cunho neurológicos, em nivel celular ou não. Isso } \\
\text { pode causar transtornos, sindromes e outras } \\
\text { variáveis futuramente. }\end{array}$ \\
\hline $\begin{array}{c}\text { NUNES et al., } \\
2020\end{array}$ & $\begin{array}{l}\text { Revisão } \\
\text { Integrativa }\end{array}$ & $\begin{array}{c}\text { Disfunções olfativas com preval ência entre } 30 \text { a } \\
88 \% \text { dos pacientes com COVD-19 englobados nos } \\
\text { diferentes estudos. Relados por pacientes com } \\
\text { quadros leves e moderados da doença. Os } \\
\text { transtornos como anosmia, hiposmiahipogeusia, e } \\
\text { disgeusia são sintomas frequentes nos pacientes } \\
\text { com COVID-19. }\end{array}$ & $\begin{array}{l}\text { O envolvimento do virus com o sistema nervoso é, } \\
\text { até então, inconclusivo. Entender os sintomas } \\
\text { neurológicos, principalmente em quadros mais } \\
\text { graves, auxilia nas intervenções e nos prognósticos } \\
\text { médicos. }\end{array}$ \\
\hline $\begin{array}{c}\text { GRENDENE et } \\
\text { al., } 2021\end{array}$ & $\begin{array}{c}\text { Revisão } \\
\text { bibliográfica }\end{array}$ & $\begin{array}{c}\text { Aponta que existem poucos estudos revisados sobre } \\
\text { a ocorrência ou prevalência das sequelas de longo } \\
\text { prazo da COVID-19. Há algumas evidências de que } \\
\text { disfunções como a disosmia e disgeusia são } \\
\text { sequel as de longo prazo associadas à COVID-19. A } \\
\text { mai oria não trabalha com periodos de } \\
\text { acompanhamento indi cativos de sequelas de longo } \\
\text { prazo. }\end{array}$ & $\begin{array}{l}\text { Não se sabe muito sobre estratégias para tratamento } \\
\text { para este virus. Pesquisas clíni cas estão sendo } \\
\text { realizadas para descobrir novos tratamentos. } \\
\text { Prevenção ainda é a melhor forma de lidar. }\end{array}$ \\
\hline $\begin{array}{c}\text { KOSUGI et al., } \\
2020\end{array}$ & $\begin{array}{l}\text { Quali quantitativa } \\
\text { por questionário }\end{array}$ & $\begin{array}{c}\text { Induidos } 253 \text { pacientes, de todas as regiões } \\
\text { brasileiras, uma maioria apresentou anosmia e } 13 \text {, } \\
2 \% \text { não tiveram recuperação da per da olfativa. } \\
\text { Alteração no paladar não está incluida na pesquisa. }\end{array}$ & $\begin{array}{l}\text { Anosmia apresenta menor taxa de recu peração e } \\
\text { duração mai or em pacientes por COVID-19 } \\
\text { positivos do que nos negativos. Hiposmia teve } \\
\text { maior taxa de recuperação do que a anosmia. }\end{array}$ \\
\hline
\end{tabular}

A través de estudios de Pimentel (2020) basados en 15 publicaciones que describieron informes clínicos en Europa a principios de 2020, se identificaron casos de hiposmia, anosmia, fantosmia y parosmia, con prevalencia entre el $22,7 \%$ y el $88,8 \%$, asociada o no a hipogeusia y ageusia.

La amplitud de las tasas de síntomas sensoriales/secuelas se debe a la diferencia entre los estudios, así como a los instrumentos utilizados por estas variadas investigaciones científicas, e incluso a las diferencias genéticas en la población (Pimentel, 2020). Las diferencias de población muestran que las tasas de ocurrencia de anomalías del gusto olfativo son más altas, por ejemplo, en poblaciones de Europa, África del Norte, Asia meridional y Asia occidental, en comparación con las tasas más bajas presentadas por pacientes en Asia oriental (Santos et al., 2020). 
Las mujeres y las personas más jóvenes parecen ser las más afectadas por los trastornos olfativos y gustativos (Costa et al., 2020; Nascimento, 2020). Esta diferencia probablemente se produce porque existe una diferencia en la reacción de defensa fisiológica entre los grupos de edad y los géneros de la especie humana (Cardoso et al., 2020).

El estudio de Santos et al. (2020) destaca que las disfunciones olfativas y gustativas como síntomas iniciales, y que tiene mayor repercusión tras el alta de los pacientes.

El tratamiento hospitalario de los pacientes termina antes de la aparición de secuelas, probablemente porque hay una deficiencia histórica de vacantes y profesionales de la salud en Brasil. El aumento del flujo hospitalario de pacientes durante la pandemia parece haber agravado la situación, impidiendo un seguimiento específico y exhaustivo, ya que la atención ya era precaria (Santo et al., 2021).

En la revisión integradora de Nogueira et al. (2021) se identificó que los problemas olfativos y gustativos ocurren previamente a diferentes intensidades. No hay evidencia científica para el tratamiento de estos trastornos.

Costa et al. (2020) identificaron que los trastornos olfativos y/o gustativos pueden ocurrir a intensidades variables, con inicio junto con síntomas previos de infección. No hay evidencia científica sobre el tratamiento de estos trastornos.

El sistema inmune humano varía según algunas características físicas y fisiológicas (Cardoso et al., 2020). La intensidad de los síntomas puede ocurrir debido a estas variaciones. En las mujeres las hormonas producidas en los ciclos menstruales, las presentes en la píldora anticonceptiva y en el tratamiento del reemplazo hormonal (para combatir los síntomas menopáusicos) afectan el sistema de defensa, haciéndolo diferente al de los hombres (Rogero et al., 2021).

La edad también es un factor para la diferencia en la aparición de los síntomas. En contra de Costa et al. (2020) y Nascimento (2020), una edad mayor parece ser más susceptible a los síntomas causados por el virus. Un intestino más viejo 
generalmente tiene una menor absorción de nutrientes y producción de células de defensa. La diferencia de concepto entre los autores puede estar relacionada con el tipo específico de síntoma (Rogero et al., 2021).

El estrés también afecta la función de defensa inmune. El sistema nervioso influye en la producción y liberación de hormonas que pueden mediar esta función (Rogero et al., 2021). Las personas más jóvenes, debido a su experiencia más corta, pueden verse más afectadas por el estrés.

En cuanto a los tratamientos estudiados en la acción contra los trastornos olfativos y gustativos, la literatura presenta el uso de corticoides (acción antiinflamatoria) de la vía oral y oral, entrenamiento olfativo, vitamina A y citrato de sodio. Existen otras alternativas terapéuticas, pero las presentadas anteriormente son más propicias para la efectividad. Sin embargo, no hay pruebas suficientes o suficientes acerca de la eficacia de estos tratamientos (Cardoso et al., 2020; Costa et al., 2020; Felipe et al., 2021; Neta et al., 2021).

A través de una revisión de la literatura (Brito e Silva, 2020), creen que hay una mayor incidencia de daño al sistema nervioso en los casos agudos del virus. Sin embargo, la clasificación de los casos agudos y crónicos aún no es consensuada.

Souza et al. (2021) concluyeron que las disfunciones deben estudiarse con más rigor y durante un período de tiempo más largo. EI COVID-19 afecta a las células olfativas del epitelio, posiblemente alterando la neurotransmisión.

El estudio de Lopes y De Abreu (2021) informa que las secuelas causadas por la enfermedad pueden ser de naturaleza neurológica, a nivel celular o no. Esto puede causar trastornos, síndromes y otras variables en el futuro.

Las disfunciones olfativas y gustativas, en general, se producen de forma asociada, ya que los sentidos olfativo y gustativo (sentidos químicos, perciben las sustancias en la cavidad nasal y oral) trabajan juntos y las sensaciones gustativas dependen exclusivamente del olfato. Las sensaciones sensoriales ocurren debido a la 
interacción de las moléculas con los receptores del olfato y el gusto. Los receptores del gusto (que se encuentran en regiones de la lengua, el paladar, la faringe, la epiglotis y el esófago) son responsables de enviar información gustativa a través de impulsos nerviosos (comunicación entre células, neuronas) al sistema nervioso central. En el olfato, la información olfativa también se transmite al sistema nervioso central a través de neuronas que se comunican por corrientes eléctricas (sinapsis) (Neto et al., 2011; Oliveira, 2014).

El virus COVID19 causa lesión a las células neuronales olfativas, pues en el epitelio nasal hay una alta cantidad de enzimas que facilitan la difusión y replicación del mismo. En respuesta a la infección el sistema inmune "activa" el sistema de defensa mediante citosinas (proteínas), el llamado efecto ciopático, que puede comprometer el proceso de neurotransmisión, provocando pérdida olfativa. Esto también ocurre con el gusto, donde el proceso inflamatorio (efecto citopático) disminuye la vida de las células receptoras de las papilas gustativas (Cardoso et al., 2020; Felipe et al., 2021)

Los análisis científicos demuestran la probabilidad de que el virus llegue directamente al epitelio nasal, no a las neuronas. Las células del epitelio nasal retienen el llamado equilibrio iónico de moco, del que dependen las neuronas para hacer las sinapsis hasta el sistema nervioso central. Cuando este equilibrio se ve afectado, el olor deja de funcionar como debería, puede producir daño a las neuronas olfativas. Aún así, no hay pruebas de si la anosmia es el resultado directo del virus o si es el resultado de una respuesta inmunológica (Nishioka, 2020).

En el sentido gustativo, las células receptoras gustativas no se ven afectadas por el virus, sino por las células de soporte, lo que puede explicar los casos de pérdida del gusto. El epitelio olfativo tiene la capacidad de regenerarse, es decir, la anosmia se considera reversible, sin embargo, los pacientes con recuperación lenta de esta disfunción pueden presentar otro trastorno, la parosmia, en el que se recuperan los sabores (dulce, amargo, salado, agrio), pero ciertos olores y aromas se vuelven desagradables (Nishioka, 2020). 
Nunes et al. (2020), en su revisión, encontraron que la participación del virus con el sistema nervioso no es, hasta entonces, concluyente. Comprender los síntomas neurológicos, especialmente en afecciones más graves, ayuda en las intervenciones y los pronósticos médicos.

La implicación del virus con el sistema nervioso parece no ser concluyente. Actualmente, existen dos teorías principales que explican los impactos neurológicos del COVID-19 en los seres humanos, la primera corresponde a la acción del virus en la desregulación inmune, como la sobreproducción de citocinas, y por lo tanto causando síntomas neurológicos. Indicando la posibilidad de que el virus se propague a través de la sangre y las vías neuronales hacia el sistema nervioso. El segundo sugiere que la infección en el sistema nervioso central ocurre a través de neuronas periféricas infectadas por el virus (Felipe et al., 2021).

Brito e Silva (2020), Pimentel (2020), Santos et al. (2020) y Nogueira et al. (2021) coinciden en el poco conocimiento que existe hoy en día y proponen la continuidad de estudios sobre los síntomas del COVID 19. Esto es importante porque a través de estudios científicos será posible definir las causas de los mecanismos que causan cambios en el gusto olfativo y proporcionar una base para la investigación de tratamientos adecuados para los afectados (Nishioka, 2020; Santos et al., 2020; Felipe et al., 2021; Lima et al., 2021; Oliveira et al., 2021).

En la revisión de la literatura por Grendene et al. (2021) la conclusión indica que no se sabe mucho sobre las estrategias de tratamiento de este virus. Es por eso que se están llevando a cabo investigaciones clínicas para descubrir nuevos tratamientos. La prevención hoy en día sigue siendo la mejor manera de lidiar con la infección.

Las medidas de prevención contra el virus incluyen: higiene de manos a Pimentel, realizada lavándose con agua y jabón (rompiendo la pared lipídica del virus y matándola) y / o usando alcohol etílico al 70\%, evitando las manos con ojos, nariz y boca, practicando el etiquetado respiratorio (cuidado al toser o estornudar), usar máscaras faciales (barrera física contra las gotitas colgantes), distanciamiento social de al menos un metro, desinfección de objetos y superficies, mantenerse en 
aislamiento sintomático, anestesiar en interiores, evitar apretones de manos y abrazos y evitar el contacto social. Todos están indicados de acuerdo con la base científica (Stephens et al., 2009; Baptista y Fernandes, 2020; García, 2020; Soares et al., 2021; Spdm, 2021)

En relación con el aislamiento social, los estudios indican su eficacia y ayuda a reducir las tasas de infección, sin embargo, debe hacerse en asociación con otras meditaciones de contención del virus (Who, 2021). También hay pruebas sobre la aireación de lugares cerrados cuando se exponen a la luz solar y mantenerlos ventilados, porque tales ambientes contienen las gotas de vapor de agua de la tos, los estornudos y el acto mismo de hablar de individuos (Opas, 2021). El uso de mascarillas está científicamente comprobado, se sabe que este EPI (equipo de protección personal) es una barrera física, una pared, contra el virus COVID-19 (Salles et al, 2021). Además, se enfatiza que incluso después de la vacunación las personas no deben dejar de usar/ aplicar los mecanismos de prevención contra el virus (Brasil, 2021a).

Kosugi et al. (2020) realizaron una encuesta online y concluyeron que la anosmia tiene una menor tasa de recuperación y una mayor duración en pacientes positivos de covid-19 que en pacientes negativos. La hiposmia tuvo una mayor tasa de recuperación que la anosmia.

En la hiposmia, debido a que es una pérdida parcial, es posible "entrenar" el olor. Los olores y los aceites esenciales se utilizan dos veces al día durante seis meses para este propósito. Ya más severa la pérdida, anosmia, si no hay recuperación instantánea el tratamiento es farmacológico y prolongado (Pereira et al., 2020). Esto probablemente explica la diferencia en las tasas de recuperación de ambas secuelas. 


\section{CONCLUSIONES}

Las secuelas del COVID-19 son diversos trastornos que comprometen los sentidos sensoriales (olfato y gusto) en diferentes grados, afectando el bienestar y la vida cotidiana de miles de personas.

Las mujeres y los jóvenes son los más afectados por estas disfunciones. No se sabe exactamente cómo el virus causa los síntomas neurológicos en los pacientes, y los medios exactos por los cuales ocurren las disfunciones. Además, no existen tratamientos específicos y científicamente probados para las diversas disfunciones, pero el más indicado es la práctica del entrenamiento olfativo.

Los estudios relacionados con disfunciones son limitados, principalmente, en Brasil y cuando se analizan como secuelas, es decir, se estudian después de un cierto período después de la recuperación de los pacientes con COVID-19. La continuidad de la investigación científica es indispensable, porque solo este proceso podrá dilucidar las dudas que aún existen y generar tratamientos adecuados para las personas que desarrollaron COVID-19 y se quedaron con algunos de los diversos tipos de secuelas, incluidas las sensoriales.

\section{REFERENCIAS}

BAPTISTA, A. B.; FERNANDES, L. V. COVID-19, análise das estratégias de prevenção, cuidados e complicações sintomáticas. Revista Desafios, v. 7, p. 1-10, 2020.

BARROS, Ó. D. et al. Disgeusia: a propósito de um caso clínico. Revista Portuguesa De Medicina Geral E Familiar, v. 31, n. 4, p. 272-276, 2015.

BRANDÃO, R. E. L. Vírus e Retrovírus: Contributo para a Evolução das Espécies. 2015. 61p. (Mestrado). Faculdade de Ciências da Saúde, Universidade Fernando Pessoa, Porto PT. 
BRASIL. Coronavírus - Como é transmitido? , Brasília DF, 2021. Disponível em: < https://www.gov.br/saude/pt-br/coronavirus/como-e-transmitido >. Acesso em: 06 set 2021.

- Doenças ocasionadas por vírus respiratórios emergentes, incluindo o COVID-19. Brasília DF, 2021a. Disponível em: < https://www.unasus.gov.br/cursos/curso/46164 >. Acesso em: 06 set 2021.

BRITO, W. G. F.; SILVA, J. P. D. O. Impactos neuropatológicos do COVID-19. Brazilian Journal of Health Review, v. 3, n. 3, p. 4227-4235, 2020.

CAPES. Treinamento no uso do Portal de Periódicos. Brasilia DF, 2012. Disponível em: < https://www.fca.unesp.br/Home/Biblioteca/portal-capes.pdf >. Acesso em: 06 set 2021.

CARDOSO, A. R. Olfato como Marcador Biológico. 2018. 21p. (Mestrado). Universidade de Lisboa, Lisboa PT.

CARDOSO, M. D. C. et al. Anosmia e disgeusia no paciente com coronavírus: revisão narrativa. REAS/EJCH, v. 46, p. 1-8, 2020.

COSTA, K. V. T. D. et al. Desordens olfativas e gustativas na COVID-19: uma revisão sistemática. Braz J Otorhinolaryngol., v. 86, n. 6, p. 781-792, 2020.

ESTRELA, M. C. A. et al. Covid-19: sequelas fisiopatológicas e psicológicas nos pacientes $e$ na equipe profissional multidisciplinar. Brazilian Journal of Development, v. 7, n. 6, p. 59138-59152, 2021.

FELIPE, L. P. et al. Compreensão das manifestações neurológicas induzidas por infecções pelo novo coronavírus: uma revisão integrativa. REAID, v. 95, n. 36, p. e21137, 2021.

FILHO, N. D. A. O que é saúde? Rio de Janeiro RJ: Editora Fiocruz, 2011. 160p. 
GARCIA, L. P. Uso de máscara facial para limitar a transmissão da COVID-19. Epidemiol. Serv. Saude, v. 29, n. 2, p. 1-4, 2020.

GOMES, D. R. D. P. et al. Avaliação do paladar de idosos e sua relação com estado nutricional e hábitos alimentares. Pan American Journal of Aging Research, v. 8, n. 1, p. 1-8, 2020.

GRENDENE, C. S.; GULO, R. B.; BETIOL, R. S. M. Coronavírus (covid-19): história, conhecimento atual e sequelas de longo prazo. Revista Corpus Hippocraticum, v. 1, n. 1, p. 1-14, 2021.

ISER, B. P. M. et al. Definição de caso suspeito da COVID-19: uma revisão narrativa dos sinais e sintomas mais frequentes entre os casos confirmados. Epidemiol. Serv. Saude, Brasília, v. 29, n. 3, p. 1-11, 2020.

KOSUGI, E. M. et al. Recuperação incompleta e tardia da perda súbita do olfato na COVID-19. Braz. j. otorhinolaryngol., v. 86, n. 4, p. 490-496, 2020.

LIMA, J. H. C. et al. Covid-19 e os danos ao aparelho olfatório causando anosmia. Revista Científica Multidisciplinar, v. 2, n. 8, p. e28665, 2021.

LOPES, D. O.; DE ABREU, F. Eletroterapia IVL no tratamento de Covid-19 e sequelas no sistema nervoso central. Brazilian Journal of Development, v. 7, n. 4, p. $42332-423402021$.

MACHADO, A. L. M.; MACHADO, M. C. M. Disgeusia: Revisão de Literatura. 2020. 56p. (Graduação). Universidade de Uberaba, Uberaba MG.

NASCIMENTO, M. A. Alteração das funções sensoriais de olfato e paladar e seus correlatos clínicos e funcionais em indivíduos com Covid-19. 2020. 71p. (Mestrado). Universidade Federal do Rio Grande do Norte, Santa Cruz. 
NETA, F. I. et al. Pathophysiology and possible treatments for olfactory-gustatory disorders inpatients affected by COVID-19. Current Research in Pharmacology and Drug Discovery, v. 2, p. 1-11, 2021.

NETO, F. X. P. et al. Anormalidades sensoriais: Olfato e paladar. Arquivos Int. Otorrinolaringol., v. 15, n. 3, p. 350-358, 2011.

NISHIOKA, S. D. A. A perda de olfato na COVID-19 já tem explicação - pelos menos em parte. 2020. Disponível em: < https://www.unasus.gov.br/especial/covid19/markdown/335 >. Acesso em: 30 out 2021.

NOGUEIRA, J. F. et al. Distúrbios olfatórios decorrentes de infecção por SARSCoV-2: fisiopatologia, fatores de risco e possíveis intervenções. Research, Society and Development, v. 10, n. 11, p. 1-7, 2021.

NUNES, L. T. D. et al. Principais Manifestações Neurológicas decorrentes do COVID-19: uma revisão integrativa. Revista Saúde Coletiva, v. 10, n. 59, p. 42484254, 2020.

OLIVEIRA, A. A. D. et al. Análise dos principais fatores de risco preexistentes em pacientes diagnosticados com a COVID-19 no Amapá, Amazônia, Brasil. Revista Científica Multidisciplinar Núcleo do Conhecimento, v. 17, p. 56-72, 2021. Disponível em: < https://www.nucleodoconhecimento.com.br/saude/riscopreexistentes $>$.

OLIVEIRA, F. V. Aromas: contextualizando o ensino de Química através do olfato e paladar. 2014. 137 p. (Mestrado). Universidade de Santa Maria, Santa Maria RS.

OMS. Série de documentos de informação sintéticos do escritório regional da oms para a áfrica sobre a COVID-19. Africa, p. 1-6, 2021. Disponível em: < https://apps.who.int/iris/bitstream/handle/10665/338819/WHO-AF-ARD-DAK-102021-por. pdf? sequence=1\&isAllowed=y >. Acesso em: 30 out 2021. 
OPAS. Roteiro para melhorar e garantir a boa ventilação de ambientes fechados no contexto da doença causada pelo novo coronavirus, COVID-19. Washington D.C., 2021. Disponível em: < https://iris.paho.org/handle/10665.2/53938 >. Acesso em: 01 out 2021.

PEREIRA, A. C. C. M. et al. Revisão bibliográfica: Anosmia no COVID-19. Revista Cien, v. 15, n. 2, p. 96-, 2020.

PIMENTEL, B. N. As disfunções olfativas e gustativas como apresentação clínica da COVID-19. Research, Society and Development, v. 9, n. 8, p. e64985072, 2020.

ROGERO, M.; NATACCI, L.; AMANCIO, O. Nutrição \& Imunidade. São Paulo SP: SBAN, 2021. 27p.

SANTO, D. M. N. D. E. et al. Desafios do enfermeiro do Centro Cirúrgico frente à pandemia da COVID-19 e transição de uma sala cirúrgica em unidade de terapia semi-intensiva. REAS, v. 13, n. 6, p. 1-6, 2021.

SANTOS, I. H. A. et al. Disfunções olfativas e gustativas na COVID-19. Research, Society and Development, v. 9, n. 12, p. e42591211363, 2020.

SESAPR. Reabilitação do paciente pós tratamento de infecção por SARS- CoV-2. Curitiba $\quad 2020$ PR, Disponível em: < https://www.saude.pr.gov.br/sites/default/arquivos_restritos/files/documento/202012/Nota\%20orientativa\%20n\%C2\%BA\%2053\%20reabilita\%C3\%A7\%C3\%A3o.pdf >. Acesso em: 09 set 2021.

SILVA, A. W. C. et al. Caracterização clínica e epidemiologia de 1560 casos de COVID-19 em Macapá/AP, extremo norte do Brasil. Research, Society and Development, $\quad$ v. 9 , n. 8, p. 1-21, 2020a. Disponível em: < https://rsdjournal.org/index.php/rsd/article/view/5499/4641 >.

SILVA, A. W. C. et al. Perfil epidemiológico e determinante social do COVID-19 em Macapá, Amapá, Amazônia, Brasil. Revista Científica Multidisciplinar Núcleo do 
Conhecimento, v. 4, n. 4, p. 05-27, 2020. Disponível em: < https://www.nucleodoconhecimento.com.br/saude/covid-19-em-macapa >.

SOARES, K. H. D. et al. Medidas de prevenção e controle da covid-19: revisão integrativa. Revista Eletrônica Acervo Saúde, v. 13, n. 3, p. 1-11, 2021. Disponível em: < https://doi.org/10.25248/reas.e6071.2021 >.

SOUZA, F. D. S. et al. "Anarquia do paladar" e anosmia pós-COVID-19: Seriam danos permanentes? Relato de casos. Revista de Ciências Biológicas e da Saúde, v. 4, n. 1, p. 1-6, 2021.

SOUZA, K. O. et al. Covid-19 e o cenário atual da Cidade de Castanhal PA, Brasil. Research, Society And Development, v. 9, n. 8, p. 1-17, 2020. Disponível em: < https://rsdjournal.org/index.php/rsd/article/view/5717/4998 >.

SPDM. HMB explica por que a higienização das mãos auxilia na prevenção da Covid-19. São Paulo SP, 2021. Disponível em: < https://www.spdm.org.br/saude/noticias/item/3390-hmb-explica-por-que-ahigienizacao-das-maos-auxilia-na-prevencao-da-covid-19 >. Acesso em: 04 out 2021.

STEPHENS, P. R. S. et al. Virologia. In: MOLINARO, E. M.;CAPUTO, L. F. G., et al (Ed.). Conceitos e métodos para a formação de profissionais em laboratórios de saúde. Rio de Janeiro RJ: EPSJV, v.4, 2009. p.125 - 220.

THEY, N. H. Você sabe o que é um vírus? Microbiologando Porto Alegre RS, 2020. Disponível em: < https://www.ufrgs.br/microbiologando/voce-sabe-o-que-eum-virus/ >. Acesso em: 06 set 2021.

UZUN, A. C. D. S. B. Sequelas da Covid-19 vão além da fadiga, ressalta especialista. Campo Grande MS, 2020. Disponível em: < http://www.ms.gov.br/sequelas-da-covid-19-vao-alem-da-fadiga-ressalta-especialista/ >. Acesso em: 06 set 2021. 
VANA, L. P. M.; SCHIOZER, W. Sequelas de queimaduras: nova classificação. Rev Bras Queimaduras, v. 12, n. 3, p. 192, 2013.

Enviado: noviembre de 2021.

Aprobado: noviembre de 2021. 